\title{
Genetic Diversity of Bacterial Blight Resistant Rice (Oryza sativa L.) Genotypes from INGER
}

\author{
F Akter ${ }^{1 *}$, M Z Islam $^{3}$, A Akter ${ }^{4}$ S K Debsharma ${ }^{2}$, A Shama ${ }^{5}$ and M Khatun ${ }^{2}$
}

\begin{abstract}
Genetic diversity of 65 rice genotypes was studied from IRBBN (International Rice Bacterial Blight Nursery) of INGER (International Network for Genetic Evaluation of Rice) materials through Mahalanobis $\mathrm{D}^{2}$ statistic for grain yield and yield contributing characters. The genotypes were grouped into five clusters. The inter-cluster distances were higher than intra-cluster distances indicating wider genetic diversity among the genotypes of different clusters. The intra-cluster distances were lower in all the cases reflecting homogeneity of the genotypes within the clusters. The cluster III contained the highest number of genotypes (23) and the clusterv contained the lowest (8). The highest intra-cluster distance was noticed for the cluster I and lowest for cluster III. The highest inter-cluster distance was observed between cluster I and V, followed by cluster IV and V, cluster II andV and the lowest between cluster I and IV. Regarding inter-cluster distance, the genotypes of cluster $\mathrm{V}$ showed high genetic distance from all other clusters. The genotypes from cluster $\mathrm{V}$ could be hybridized with the genotypes of other clusters for producing transgressive segregants. Based on canonical vector analysis, panicle number per plant had maximum contribution towards genetic divergence. The highest cluster means for yield, grain/panicle and spikelet fertility were obtained from cluster V. The highest means for 1000 grain weight, second higher yield and the lowest growth duration were found in cluster II, while the lowest mean value for yield and 1000 grain weight and higher mean value for growth duration were found in cluster IV. The crosses between the genotypes/parents of cluster V and cluster II, cluster V and cluster I would exhibit high heterosis as well as higher level of yield potential. Therefore, more emphasis should be given for selection of the genotypes from clusters II and $\mathrm{V}$ for future breeding programme.
\end{abstract}

Key words: Genetic diversity, $\mathrm{D}^{2}$ analysis, cluster analysis, rice (Oryza sativa L.), INGER

\section{INTRODUCTION}

Rice (Oryza sativa L.) is considered as the major crop in Bangladesh as it constitutes $91.8 \%$ of the total food grain (rice, wheat and maize) production of 37.50 million metric tons (BBS 2012-2013). Although Bangladesh is now on the verge of attaining self sufficiency in cereal production, there is still a large gap between the production and demand. Among other ecosystems, rainfed condition (T. Aman) is the most suitable for growing rice in this country. Area under T. Aman is the highest which is about $49.63 \%$ of total rice land and contributes $40.57 \%$ of the total rice production (BBS 20112012). Agronomic value of rice variety depends on many characteristics. The most important features include high yielding ability, resistance to diseases and pests, resistance to undesirable environmental factors, and high quality of the products (Aljumailiet al., 2018).

Genetic diversity studies occupy an important position in breeding and improvement programme as they ensure efficient utilization of germplasm resources and effective breeding system for the improvement of closely related crop species. Genetic variation analysis helps breeders in observing germplasm as well as predicting possible genetic potentials. Geneticallydistant parents usually able to produce higher 
heterosis(Chakravarthi et al., 2006). It is a powerful tool to determine the genetic discrimination among the genotypes which can be used to select appropriate parental genotypes for hybridization to develop high yielding potential variety (Bhatt 1970). A clear understanding of genetic diversity is essential for the effective conservation and utilization of rice genetic resources (Tu et al. 2007, Siddique et al. 2011 and Islam et al. 2017). Precise information on the nature and degree of genetic diversity helps the plant breeder in choosing the diverse parents for purposeful hybridization (Samsuddin 1985) as cited by Biswash et al. 2016. This genetic diversity is essential to decrease crop vulnerability to abiotic and biotic stresses, ensure long-term selection grain in genetic improvement and promote rational use of genetic resource (Cortese et al., 2010).

The assessment of genetic diversity among parents used in plant breeding programmes is a necessary prerequisite to assure continuous improvement (Fuentes et al. 2005 and Islam et al. 2017). Considering this point, about 65 rice genotypes from INGER materials were cultivated. Classify of these genotypes into clusters to select entries as prospective parents to develop transgressive segregants. The present study was undertaken to assess the extent of genetic variability in 65 rice genotypes from INGER.

\section{MATERIALS AND METHODS}

Sixty-five rice genotypes from IRBBN (International Rice Bacterial Blight Nursery) of the INGER (International Network for Genetic Evaluation of Rice) materials were grown at BRRI, HQ, Gazipur farm during T. Aman 2016 season. The trial was conducted in a randomized complete block design with three replications. Thirty-two-day-old seedlings were transplanted using single seedling per hill at a spacing of $25 \mathrm{~cm} \times 15 \mathrm{~cm}$. The unit plot size was $5.4 \mathrm{~m} \times 4$ rows. Fertilizers urea, TSP, MOP, gypsum and zinc sulphate were applied (a) 160:52:85:60:12 $\mathrm{kg} \mathrm{ha}^{-1}$. All the fertilizers except $\mathrm{N}$ were applied at final land preparation. Nitrogen was applied in three equal splits, at 15 days after transplanting (DAT), at 30 DAT and just before flowering. Intercultural operations and pest control measures were done as and when necessary. Days to $50 \%$ flowering, $80 \%$ maturity, plant height $(\mathrm{cm})$, panicle number per plant and grain yield $(\mathrm{kg} / \mathrm{plot})$ data were taken and adjusted at $14 \%$ moisture level. Ten plants from each entry were randomly selected for recording 1000 grain weight (g), filled grains/panicle and unfilled grains/panicle data.The data were analyzed following principal component analysis (PCA) and Mahalanobis's (1936) generalized distance $\left(D_{2}\right)$ extended by Rao (1952). Intra and inter-luster distances were calculated by the methods of Singh and Chaudhary (1985). All statistical analyses were carried out using Genstat 5.5.

\section{RESULTS AND DISCUSSION}

Analysis of variance showed significant differences among the 65 advanced lines of IRBBN (International Rice Bacterial Blight Nursery) for all of the seven characters under study, indicating the presence of notable genetic variability among the genotypes. The principal component analysis showed that the first component accounted for $80 \%$ of the total variation. Based on the degree of divergence, 65 genotypes were grouped into five clusters on the basis of cluster analysis (Table 1). Maximum 23 entries were grouped into the cluster III followed by 13 in cluster II and 12 in cluster I. The cluster I and II contained the lowest (8-9) number of genotypes. 
Table 1. Distribution of some advanced lines of IRBBN (International Rice Bacterial Blight Nursery) in different clusters on the basis of seven characters.

\begin{tabular}{|c|c|c|c|}
\hline $\begin{array}{l}\text { Cluster } \\
\text { no. }\end{array}$ & $\begin{array}{l}\text { No. of } \\
\text { genotypes }\end{array}$ & Entry no. & Designation \\
\hline I & 12 & $\begin{array}{l}1,3,7,9,10,19,21,22,23,25 \\
26,42\end{array}$ & $\begin{array}{l}\text { IRBB1, IRBB3, IRBB8, IRBB11, IRBB13, IRBB57, IRBB59, IRBB60, } \\
\text { IRBB61, IRBB63, } \\
\text { IRBB64, IR09N516 }\end{array}$ \\
\hline II & 13 & $\begin{array}{l}2,4,5,6,8,11,12,14,17,27 \\
28,30,64\end{array}$ & $\begin{array}{l}\text { IRBB2, IRBB4, IRBB5, IRBB7, IRBB10, IRBB14, IRBB21, IRBB51, } \\
\text { IRBB54, IRBB65, IRBB66, HHZ5-DT20-DT3-Y2, IR10L139 }\end{array}$ \\
\hline III & 23 & $\begin{array}{l}13,18,20,32,33,34,35,36 \\
40,41,45,48,49,51,52,53 \\
54,57,60,61,62,63,65\end{array}$ & $\begin{array}{l}\text { IRBB50, IRBB55, IRBB58, IR05N412, IR81373-119-2-2-1, IR81852- } \\
\text { 120-2-1-3, IR82492-7-2-3-3, IR08N194, IR09A133, IR09N127, } \\
\text { IR10A199, IR10A314, IR10A318, IR10F221, IR11A314, IR10F365, } \\
\text { IR10L185, IR10N375, IR78101-68-1-1-2-2, IR82786-43-3-2-1, } \\
\text { IR07A166, IR09L324, TN1 }\end{array}$ \\
\hline IV & 9 & $16,31,38,39,43,44,47,50,55$ & $\begin{array}{l}\text { IRBB53, IRO5A272, IR04A216, IR09L337, IR10A237, IR10A136, } \\
\text { IR10A287, IR10A325, IR10N278 }\end{array}$ \\
\hline $\mathrm{V}$ & 8 & $15,24,29,37,46,56,58,59$ & $\begin{array}{l}\text { IRBB52, IRBB62, 12DS-GMET-22, IR08N210, IR10A231, IR10N305, } \\
\text { IR10N396, IR11A108 }\end{array}$ \\
\hline
\end{tabular}

Table 2 presents intra and inter-cluster distances. Average intra- and inter-cluster distance for the entire genotypes based on phenotypic traits was determined. Considerable variation occurred in intracluster distances (ranging from 0.2456 in cluster III to 0.5134 in cluster I), indicating significant diversity prevailing among genotypes within clusters. Here the highestintra cluster value was 0.5134 and the highest inter-cluster value was 9.86, which clearly indicated variability in the genotypes of different clusters. However, lower intra cluster values in clusters III $(0.2456)$ and V (0.3064) was observed due to lower variation in all morpho-agronomic data within these groups. The intra-cluster distances were low for all the five clusters with the range of 0.2456 in cluster III to 0.5134 in cluster I which indicated homogeneous nature of the genotypes within the clusters.

The results are supported by those of Islam et al. (2014) in rice. The inter-cluster distances ranged from 3.061 to 9.860 and PCA scores also indicated a high degree of genetic diversity among the genotypes.
Regarding inter-cluster distance, cluster $\mathrm{V}$ showed the maximum genetic distance (9.860) from cluster I followed by 7.834 from cluster IV and 6.837 from cluster II and so on. It is obvious that in most of the cases cluster $\mathrm{V}$ produced the highest inter-cluster distances than the other clusters suggesting wide diversity of the genotypes within cluster $\mathrm{V}$ with the genotypes of other clusters. The genotypes in these clusters could be used as parents in hybridization programme for getting transgressive segregants (Saini and Kaiker, 1987). Moderate inter-cluster distance was observed between cluster III and I (5.882), followed by cluster V and III (4.271). The minimum inter-cluster diversity was observed between cluster IV and I (3.061), cluster IV and II (3.233), cluster II and I (3.301), cluster III and II (3.504) and cluster IV and III (3.565) indicating that the genotypes of these clusters were genetically close. The inter-cluster distances in all the clusters were higher than the intracluster distances suggesting wider genetic diversity among the genotype of different groups. The results were in agreement with Islam et al. (2019) and Akter et al. (2016). 
Table 2. Intra (bold) and inter-cluster distances $\left(D_{2}\right)$ of 65 advanced lines from IRBBN (International Rice Bacterial Blight Nursery).

\begin{tabular}{cccccc}
\hline Cluster & I & II & III & IV & V \\
\hline I & $\mathbf{0 . 5 1 3 4}$ & 3.301 & 5.882 & 3.061 & 9.860 \\
II & & $\mathbf{0 . 3 7 8 6}$ & 3.504 & 3.233 & 6.837 \\
III & & & $\mathbf{0 . 2 4 5 6}$ & 3.565 & 4.271 \\
IV & & & & $\mathbf{0 . 3 8 1 7}$ & 7.834 \\
V & & & & & $\mathbf{0 . 3 0 6 4}$ \\
\hline
\end{tabular}

The highest cluster means for yield, grain/panicle and spikelet fertility were obtained from cluster V (Table 3). The highest (TGW), second highest yield and lowest growth duration and plant height were found in cluster II. While the lowest mean value for yield, TGW and second lower grain/panicle and longer growth duration were found in cluster IV and the lowest panicle number/plant and highest mean value for plant height and growth duration were found in cluster III.

Mean performance of different clusters for the characters studied revealed that lower TGW, grain/panicle, longer growth duration and low yielding ( $\mathrm{t}$ ha-1) genotypes were clubbed into cluster IV whereas higher yield, grains/panicle and spikelet fertility and other second highest yield contributing characters (taller plant, TGW) were obtained in cluster V. Maximum good characters were accumulated in cluster $\mathrm{V}$ and as a result higher yield (4.36 $\left.\mathrm{t} \mathrm{ha}^{-1}\right)$ was obtained in this cluster. It was interesting that considering cluster distances, the cluster $\mathrm{V}$ showed comparative higher estimates of inter clustervalues than all other clusters. Therefore, the genotypes of cluster $\mathrm{V}$ can be used in hybridization programme to produce higher yielding genotypes with all other clusters.

Joshi and Dhawan (1966) reported that inclusion of more diverse parents (within a limit) is believed to increase the chances for obtaining stronger heterosis and give broad spectrum of variability in segregating generations. Therefore, more emphasis should be given on cluster $\mathrm{V}$ and II for selecting genotypes as parents for crossing with the genotypes of cluster IV which may produce new recombinants with desired traits. Cluster IV had the lowest cluster mean value for grain/panicle, TGW and also lower grain yield. It was also noticed that yield performance in six clusters was highly variable. On the other hand, the highest panicle number/panicle was observed in cluster I. However, yield was comparatively lower due to lower grain/panicle and spikelet fertility. So yield improvement of cluster I is possible by crossing with cluster V. Such results reflected that all these advanced lines are genetically distant from each other.

Table 3. Cluster means for seven characters of 65 advanced lines from IRBBN.

\begin{tabular}{lcccccc}
\hline \multirow{2}{*}{ Character } & \multicolumn{7}{c}{ Cluster number } \\
\cline { 2 - 6 } & $\mathrm{I}$ & $\mathrm{II}$ & $\mathrm{III}$ & $\mathrm{IV}$ & $\mathrm{V}$ & $\mathrm{CV}$ \\
\hline Plant height & 88.08 & 87.54 & 108.26 & 106.67 & 108.12 & 12.86 \\
Panicle number/plant & 9.58 & 9.38 & 9.00 & 9.56 & 9.25 & 16.44 \\
Growth duration (day) & 123.92 & 122.38 & 129.83 & 128.33 & 128.25 & 3.81 \\
Yield (t ha-1) & 3.51 & 3.73 & 3.62 & 3.22 & 4.36 & 17.43 \\
Grains/panicle & 83.50 & 111.23 & 131.00 & 98.00 & 178.87 & 25.64 \\
Spikelet fertility (\%) & 58.33 & 76.85 & 80.96 & 70.56 & 87.87 & 16.98 \\
1000 grain weight (g) & 21.08 & 21.85 & 21.70 & 19.56 & 21.50 & 11.28 \\
\hline
\end{tabular}


Table 4 presents contributions of the characters towards divergence. The canonicalvector analysis revealed that the vectors (vector I and II) were positive only for panicle number per plant. Such result indicated that this character contributed maximum towards divergence. It is interesting that the greater divergence in the present materials due to this character will offer a good scope for improvement of yield through rational selection of parents for producing heterotic rice hybrids. Similar findings also reported by Islam et al. (2014) and Akter et al. (2018).

It is assumed that, maximum amount of heterosis will be manifested in cross combinations involving the parents belonging to most divergent clusters. However, for a practical plant breeder, the objective is not only high heterosis but also to achieve high level of production and reducing the growth duration. In the present study, the maximum distances existed between cluster $\mathrm{V}$ and $\mathrm{I}$. However, considering the yield, grain/panicle and spikelet fertility, crosses involving the genotypes of cluster $\mathrm{V}$ and cluster I may exhibit high heterosis for yield.Again, considering growth duration and plant height, crosses between the genotypes of cluster III and II mayexhibit higher heterosisfor earliness and dwarf stature.

Table 4. Relative contributions of the seven characters towards total divergence in 65 advanced lines from IRBBN.

\begin{tabular}{lcc}
\hline Trait & Vector 1 & Vector 2 \\
\hline Plant height & -0.0327 & -0.0774 \\
Panicle number/plant & 0.1208 & 0.0058 \\
Growth duration & -0.0388 & -0.1067 \\
Yield (t ha-1) & -0.0485 & 0.6809 \\
Grains / panicle & -0.0792 & 0.0121 \\
Spikelet fertility $(\%)$ & -0.0462 & 0.0228 \\
1000 grain weight $(\mathrm{g})$ & -0.0616 & 0.1744 \\
\hline
\end{tabular}

Similarly, the genotypes of cluster $\mathrm{V}$ might be crossed with the genotypes of cluster II to get higher grain yield along with earliness. Mian and Bahe (1989) reported that the parents separated by medium magnitude of intercluster distance generally showed higher heterosis in chickpea. Similar findings were also reported by Khalequzzaman et al. (2008) for rice.

\section{CONCLUSION}

Based on the results of the current study, it was observed that there was a high level of genetic diversity among the genotypes included in cluster V. In addition highest yield and yield contributing characters were produced by the genotypes of cluster $\mathrm{V}$. The crosses involving parents belonging to maximum divergent clusters were expected to manifest maximum heterosis and also wide genetic variability. A higher heterosis could be produced from the crosses between genetically distant parents (Ghaderi et al., 1984). Keeping this in view, it appeared that crosses between the genotypes belonging to cluster $\mathrm{V}$ and cluster I, cluster V and cluster II would exhibit high heterosis as well as higher level of yield potential. So, based on this result, the genotypes under cluster II (IRBB2, IRBB4, IRBB5, IRBB7, IRBB10, IRBB14, IRBB21, IRBB51, IRBB54, IRBB65, IRBB66, HHZ5-DT20DT3-Y2, IR10L139) and cluster V (IRBB52, IRBB62, 12DS-GMET-22, IR08N210, IR10A231, IR10N305, IR10N396, IR11A108) have been identifed as diverse genotypes and suitable as a parent in the future breeding programme.

\section{REFERENCES}

Akter, N, H Begum, M Z Islam, M A Siddique and M Khalequzzaman. 2018. Genetic diversity in aus rice (Oryza sativa 1.) genotypes of Bangladesh. Bangladesh J. Agril. Res. 43(2): 253-266. 
Akter, N, M Z Islam, M A Siddique, T Chakrabarty, M Khalequzzaman and M A Z Chowdhury. 2016. Genetic diversity of Boro rice (Oryza sativa L.) landraces in Bangladesh. Bangladesh J. Pl. Breed. Genet. 29 (2): 33-40.

Aljumaili, S J, M Y Rafii, M A Latif, S Z Sakimin, I W Arolu and G Miah. 2018. Genetic Diversity of Aromatic Rice Germplasm Revealed By SSR Markers. Bio Med Resear. Intern. 2018. https://doi.org/10.1155/2018/7658032

Bangladesh Bureau of Statistics (BBS). 2011-2012. Department of Agriculture Extension, Ministry of Agriculture, Govt. of Bangladesh.

Bangladesh Bureau of Statistics (BBS). 2012-2013. Bangladesh Economic Review. Ministry of Finance, Govt. of Bangladesh. Bangladesh Bureau of Statistics.

Bhatt, G M. 1970. Multivariate analysis approach to selection of parents of hybridization aiming at yield improvement in self-pollinated crops. Australian J. Agri. Resear. 21: 1-7.

Biswash, M R, M Sharmin, N M F Rahman, T Farhat and M A Siddique. 2016. Genetic Diversity in Modern T. Aman Rice Varieties of Bangladesh (Oryza sativa L.). Sains Malaysiana. 45(5): 709-716.

Chakravarthi, B K and R Naravaneni. 2006. SSR marker based DNA fngerprinting and diversity study in rice (Oryza sativa L). African J. of Biotech. 5(9):684-688.

Cortese, L, J Honig, C Miller and S Bonos. 2010. Genetic diversity of twelve switch grass populations using molecular and morphological markers. Bio. Energy Res. 3: 262-271.

Fuentes, J L, M T Cornide, A Alvarez, E Squarez and E Borges. 2005. Genetic diversity analysis of rice varieties (Oryza sativa L.) based on morphological, pedigree and DNA polymorphism data. Pl. Genet. Resour. 3(3): 353-359.

Ghaderi, A, M Shishegar, A Regai. and B Ehdaie. 1984. Multivariate analysis of genetic diversity for yield and its components in mungbean. J. Ameri. Soc. for Horti.Sci. 104: 728-732.

Islam, M Z, M A Siddique, E S M H Rashid, M S Ahmed and M Khalequzzaman. 2014. Genetic diversity in sadajira Rice (Oryza sativa L.) germplasm. The Agriculturists. 12(1): 26-32.

Islam, M Z, M A Siddique, N Akter, M FRK Prince, M R Islam, M Anisuzzaman and MAK Mian.
2019.Morpho-molecular Divergence of Restorer Linesfor Hybrid Rice (OryzasativaL.) Development. Cereal Research Communications. 47(3): 531-540, DOI: 10.1556/0806.47.2019.29

Islam, M Z, M Khalequzzaman, M A Siddique, N Akter, M S Ahmed and M A Z Chowdhury.2017. Phenotypic characterization of Jhum rice (Oryza sativa L.) landraces collected from Rangamati district in Bangladesh. Bangladesh Rice J. 21 (1): 47-57

Islam, $M$ Z, $M$ Khalequzzaman, MFRK Prince, MA Siddique, ESMH Rashid, MSU Ahmed, B R Pittendrighand M P Ali. 2018. Diversity and population structure of red rice germplasm in Bangladesh. PLoS ONE, 13 (5): e0196096. https:/ / doi.org/10.1371/journal. pone.0196096

Joshi, A B and N L Dhawan. 1966. Genetic improvement of yield with special reference to self fertilizing crops. Indian J. Genet. Pl. Breed. 26 A: 101-113.

Khalequzzaman, M, M Z Islam, K Akter and M K Bashar. 2008. Genetic diversity in local rainfed lowland rice (Oryza sativa L.) in Bangladesh. Bangladesh J. Pl. Breed.and Genet.21(1): 49-54.

Mahalanobis, P C. 1936. On the generalized distance in Statistics. Proc. Natl. Inst. Sci., India 2:49-55.

Mian, M A K and P N Bahe. 1989. Genetic divergence and hybrid performance in chickpea. Indian J. Genet. 49 (1): 119-124.

Rao, C R. 1952. Advanced statistical method in biometries research. New York, USA: John Willey and Sons Inc: 390.

Saini, H C and U S Kaiker. 1987. Genetic diversity in opium poppy. Indian J. of Genet. 91-296.

Samsuddin, A K M. 1985. Genetic diversity in relation to heterosis and combining ability analysis in spring wheat. Theor. Appl. Genet. 70: 306-308.

Siddique, M A, M Z Islam, M Khalequzzaman and M S Ahmed. 2011. Genetic diversity in rice (Oryza sativa L.) landraces of hilly areas in Bangladesh. Bangladesh J. Pl. Breed. Genet. 24(2): 25-30.

Singh, R K and B D Chaudhury. 1985. Biometrical methods in quantitative genetic analysis. New Delhi. Kalayoni publishers: 318.

Tu, M, B R Lu, Y Zhu and Y Wang. 2007. Abundant within varietal genetic diversity in rice germplasm from Yunnan Province of China revealed by SSR fingerprints. Biochemical Genet. 45: 789-801. 